\title{
Influence of vinyl acetate/ethylene copolymer powder on secondary efflorescence in Portland cement-based decorative mortar*
}

\author{
Hui-mei $\mathrm{ZHU}^{\dagger 1,2,3}$, Pei-ming WANG ${ }^{3}$, Guo-fang ZHANG ${ }^{\dagger 3}$ \\ ( ${ }^{1}$ Materials Science \& Engineering Mobile Postdoctoral Center, Xi' an University of Architecture and Technology, Xi'an 710055, China) \\ $\left({ }^{2}\right.$ College of Materials \& Mineral Resources, Xi'an University of Architecture and Technology, Xi'an 710055, China) \\ ( ${ }^{3}$ Key Laboratory of Advanced Civil Engineering Materials of Ministry of Education, Tongji University, Shanghai 201804, China) \\ †E-mail: zhuhuimeitj@163.com; zgftj@sina.com \\ Received Dec. 20, 2013; Revision accepted June 9, 2014; Crosschecked Jan. 23, 2015
}

\begin{abstract}
In this paper, the effect of redispersible vinyl acetate/ethylene copolymer powder (VAE) on the secondary efflorescence of Portland cement-based decorative mortar (PCDM) was evaluated by alkalis leachability. The secondary efflorescence substances were investigated using X-ray diffraction (XRD), X-ray fluorescence (XRF), and scanning electron microscope (SEM). The mechanism was also analyzed from the aspect of soluble components in PCDM. The results show that the secondary efflorescence level of PCDM can be quantitatively evaluated by alkalis leachability, with a higher alkali leachability indicating more obvious secondary efflorescence. VAE increases the concentrations of free alkalis ions including $\mathrm{Ca}^{2+}, \mathrm{K}^{+}, \mathrm{Na}^{+}$of $\mathrm{PCDM}$, improves the capacity of pore water transmitting ions, increases the alkalis leachability of PCDM, and accordingly promotes the secondary efflorescence of PCDM.
\end{abstract}

Key words: Portland cement-based decorative mortar (PCDM), redispersible vinyl acetate/ethylene copolymer powder (VAE), Secondary efflorescence, Alkalis leachability doi: 10.1631 jzus.A1300403

Document code: A

CLC number: TU502

\section{Introduction}

Due to its outstanding advantages, such as unique \& natural decoration, excellent weather resistance and durability, and good compatibility \& consistency with different substrates, Portland cement-based decorative mortar (PCDM) has been widely used for the decoration of exterior walls. However, the alkalis of PCDM may migrate with the evaporation of water and accumulate on the surface to form efflorescence, damaging the aesthetic effect. Efflorescence is well known as the unsightly white deposits that sometimes appear on the surfaces of

\footnotetext{
Corresponding author

* Project supported by the National Key Technology R\&D Program of China during the 12th Five-year Plan (No. 2012BAJ20B02), and the National Natural Science Foundation of China (No. 51102182) (D) ORCID: Hui-mei ZHU, http://orcid.org/0000-0003-1247-6981; Guo-fang ZHANG, http://orcid.org/0000-0002-2039-580X (C) Zhejiang University and Springer-Verlag Berlin Heidelberg 2015
}

mortar, concrete, or brickwork. Efflorescence of PCDM has received a lot of analysis, along with speculation as to its causes and preventions (Kresse, 1987; Sghaier and Prat, 2009). Efflorescence occurring during the hardening of PCDM can be referred to as 'primary efflorescence', while the effects resulting from the weathering of the hardened PCDM is referred to as 'secondary efflorescence', which is more common for PCDM. Dow and Glasser (2003) explained the efflorescence origin of Portland cement, developed a physicochemical model to explain and quantify the key features of its formation, and highlighted the important role of soluble alkalis in the efflorescence formation. The dissolution processes of alkalis and the subsequent migration with pore water have often been invoked as the driving mechanisms of efflorescence (Wang et al., 2005; Kani et al., 2012).

Redispersible polymer powder (RP) is one of the essential components of PCDM to improve adhesive 
strength. Larbi and Bijen (1990) measured the pore solution chemistry of polymer-modified mortar, and concluded that RP interacted with ions in the pore solution. Changes in covalent latex bonds due to chemical interactions with cement ions were also documented by infrared spectroscopy (Silva et al., 2002). A review of such interaction processes, mainly based on studies of ion measurements in aqueous systems, was given in (Chandra and Flodin, 1987). Redispersible vinyl acetate/ethylene copolymer powder (VAE) is the most commonly employed RP in PCDM to improve the physical and mechanical properties (Liu and Gai, 2011). However, few research focuses on the morphology of secondary efflorescence substances and the effect of VAE on the secondary efflorescence of PCDM. So the effect of VAE on the secondary efflorescence of PCDM was studied, and the effect mechanism was explored from the point of the content of soluble alkalis of PCDM and their migration. Moreover, the quantitative relationship between the alkalis leachability and the secondary efflorescence level of PCDM was illuminated.

\section{Experimental}

\subsection{Materials}

VAE, 52.5R white Portland cement according to Chinese standard GB/T2015:2005, quartz sand of 40100 meshes, iron oxide red pigment, and de-ionized water were used to prepare the PCDM specimens. The chemical composition of cement is listed in Table 1 . The bulk density of VAE is $530 \mathrm{~kg} / \mathrm{m}^{3}$, and its minimum film-forming temperature is $0{ }^{\circ} \mathrm{C}$.

Table 1 Chemical composition of white Portland cement

\begin{tabular}{cc||cc}
\hline Component & Mass (\%) & Component & Mass (\%) \\
\hline $\mathrm{Na}_{2} \mathrm{O}$ & 0.53 & $\mathrm{CaO}$ & 65.18 \\
$\mathrm{MgO}$ & 1.09 & $\mathrm{TiO}_{2}$ & 0.19 \\
$\mathrm{Al}_{2} \mathrm{O}_{3}$ & 3.61 & $\mathrm{MnO}$ & 0.04 \\
$\mathrm{SiO}_{2}$ & 20.66 & $\mathrm{Fe}_{2} \mathrm{O}_{3}$ & 0.15 \\
$\mathrm{SO}_{3}$ & 3.37 & $\mathrm{SrO}$ & 0.06 \\
$\mathrm{~K}_{2} \mathrm{O}$ & 1.96 & & \\
\hline Loss on ignition & 3.15 & & \\
\hline
\end{tabular}

\subsection{Specimen preparation}

The PCDM specimens were prepared with VAE to a cement ratio by mass of $0 \%$ and $10 \%$, with water cement mass ratio (W/C) being 0.9 , and sand to cement ratio by mass of 4 . The specimens with the dimension of $40 \mathrm{~mm} \times 40 \mathrm{~mm} \times 160 \mathrm{~mm}$ were prepared according to ISO 679:2009 and demolded after $24 \mathrm{~h}$; cylinder specimens $(\Phi 90 \mathrm{~mm} \times 5 \mathrm{~mm})$ were prepared in plastic molds, covered with plastic sheets. All these specimens were cured at $(23 \pm 2){ }^{\circ} \mathrm{C} /(60 \pm 5) \%$ relative humidity (RH) until measured.

\subsection{Test methods}

\subsubsection{Test of alkalis leachability}

As shown in Fig. 1, the upper surface of the cylinder specimen was exposed to de-ionized water $(20 \mathrm{ml})$ with other surfaces sealed off. After immersion for $4 \mathrm{~h}$, the water was completely collected and dried at $(70 \pm 2){ }^{\circ} \mathrm{C}$. Then the weight of the residue after being dried was used to calculate the alkalis leachability as (Kani et al., 2012)

$$
L_{\mathrm{a}, \mathrm{s}}=m_{1} /\left(A_{1} \cdot t\right),
$$

where $L_{\mathrm{a}, \mathrm{s}}\left(\mathrm{g} /\left(\mathrm{m}^{2} \cdot \mathrm{h}\right)\right)$ is the alkalis leachability; $m_{1}(\mathrm{~g})$ is the weight of the residue in water; $A_{1}\left(\mathrm{~m}^{2}\right)$ is the immersion surface area of the specimens; and $t(\mathrm{~h})$ is the immersion time.

\subsubsection{Test of secondary efflorescence}

PCDM was smeared on the surface of the fiber reinforced cement board to form a layer with $5 \mathrm{~mm}$ thickness. Then the specimens were soaked in deionized water for $8 \mathrm{~h}$. A digital camera was used to record the secondary efflorescence level after being dried at $23{ }^{\circ} \mathrm{C}$.

\subsubsection{X-ray diffraction analysis}

The X-ray diffraction (XRD) analysis was carried out using a powder X-ray diffraction $(\mathrm{D} / \mathrm{max}$ 2550VB3+/PC, Rigaku International Corporation, Japan) with graphite-monochromatized $\mathrm{Cu} \quad \mathrm{K} \alpha$

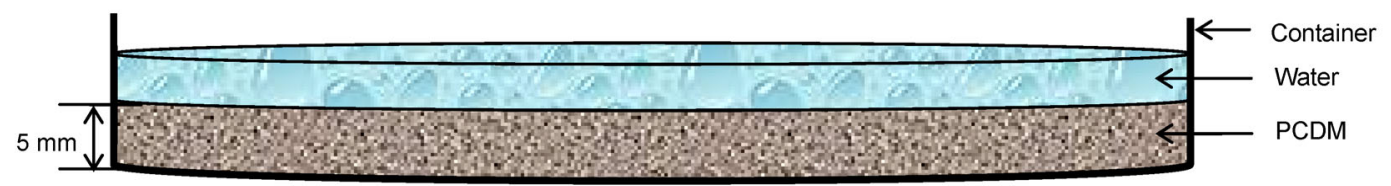

Fig. 1 Diagrammatic sketch of alkalis leachability test 
radiation generated at $40 \mathrm{kV}$ and $200 \mathrm{~mA}$. Tine-fixed step scanning was conducted with a scan speed of $10 \% \mathrm{~min}$, and the step scan was set for scattering angle $(2 \theta)$ ranges of $10^{\circ}$ to $70^{\circ}$.

\subsubsection{X-ray fluorescence analysis}

The X-ray fluorescence (XRF) analysis was conducted by a SRS3400 X-ray fluorescence spectrometer (Bruker, Germany) with an elements detection range of $\mathrm{O} 8-\mathrm{U} 92$ and a concentration range of $1-10^{6} \mathrm{mg} / \mathrm{L}$.

\subsubsection{Scanning electron microscope analysis}

The scanning electron microscope (SEM) observation for the morphology of the efflorescence zone of PCDM was carried out using a QUANTA 200FEG SEM (FEI Company, USA).

\subsubsection{Test of soluble salts content}

Powder samples of $(1 \pm 0.0001) \mathrm{g}$, finer than $80 \mu \mathrm{m}$ of the PCDM specimens, were mixed with $20 \mathrm{ml}$ de-ionized water in a covered container, stirred with a rotor for $4 \mathrm{~h}$, and then the leaching solution was completely collected and dried at $(70 \pm 2){ }^{\circ} \mathrm{C}$. The weight of the residue after being dried was used to evaluate the soluble salts content in the specimens.

\subsubsection{Test of ions concentrations}

$\mathrm{Ca}^{2+}, \mathrm{Na}^{+}$, and $\mathrm{K}^{+}$ions concentration in the leaching solution were measured by an ICPMS 7700 (Agilent, USA) inductively coupled plasma mass spectrometry, and the $\mathrm{pH}$ value was measured by a Cyberscan $5500 \mathrm{pH}$ meter (ULTRA-TECH, USA).

\subsubsection{Test of capillary water loss rate}

After being dried at $70{ }^{\circ} \mathrm{C}$ for $2 \mathrm{~d}$ and their four faces sealed by ceresin wax, the specimens with the dimension of $40 \mathrm{~mm} \times 40 \mathrm{~mm} \times 160 \mathrm{~mm}$ were immersed in water for $48 \mathrm{~h}$ for saturation, and then the specimens were dried at $40^{\circ} \mathrm{C}$ for $24 \mathrm{~h}$. The capillary water loss rate of the specimens was calculated through the mass loss of water (DIN52617:1987):

$$
W=\left(m^{\prime}-m\right) / A,
$$

where $W\left(\mathrm{~kg} / \mathrm{m}^{2}\right)$ is the capillary water loss rate; $m^{\prime}$ $(\mathrm{kg})$ is the weight of the mortar saturated with water; $m(\mathrm{~kg})$ is the weight of the specimen dried at $40{ }^{\circ} \mathrm{C}$ for $24 \mathrm{~h}$; and $A\left(\mathrm{~m}^{2}\right)$ is the dehydration area.

\section{Results and discussion}

\subsection{Secondary efflorescence}

\subsubsection{Effect of VAE on secondary efflorescence}

The secondary efflorescence pictures of PCDMs cured for $7 \mathrm{~d}$ are shown in Fig. 2. Without VAE or with 10\% VAE, the PCDM displays obvious secondary efflorescence, and the whitening zone accounts for about $60 \%$ and $80 \%$ of the total specimen area, respectively. It can be concluded that VAE promotes the secondary efflorescence of PCDM cured for $7 \mathrm{~d}$.

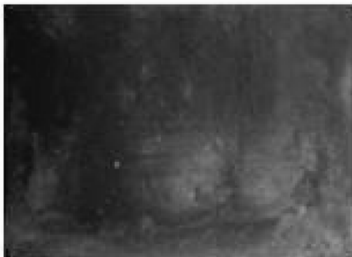

(a)

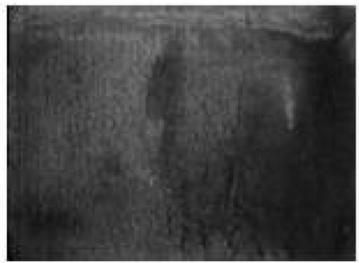

(b)
Fig. 2 Secondary efflorescence pictures of PCDMs (a) Without VAE; (b) With 10\% VAE

3.1.2 Relationship between secondary efflorescence and alkalis leachability

The extent of alkalis leachability can be used to qualitatively investigate the efflorescence levels of geopolymer pastes (Kani et al., 2012). So the extent of alkalis leachability was used to quantitatively evaluate the secondary efflorescence levels of PCDMs. The secondary efflorescence pictures of nine PCDM specimens with VAE dosage variation $(25 \%, 20 \%$, $15 \%, 10 \%, 8 \%, 6 \%, 4 \%, 2 \%$, and 0 ) cured for $7 \mathrm{~d}$ are presented in Fig. 3, and the alkalis leachability values are illustrated in Fig. 4. Five specimens of A1, A2, A3, A4, and A5 (Fig. 3) all exhibit visible secondary efflorescence, with the secondary efflorescence level gradually and slightly reducing from A1 to A5, while the alkalis leachability value decreases from $1.56 \mathrm{~g} /\left(\mathrm{m}^{2} \cdot \mathrm{h}\right)$ to $1 \mathrm{~g} /\left(\mathrm{m}^{2} \cdot \mathrm{h}\right)$. Four specimens of $\mathrm{A} 6$, A7, A8, and A9 do not display visible secondary efflorescence with their alkalis leachability all lower than $1 \mathrm{~g} /\left(\mathrm{m}^{2} \cdot \mathrm{h}\right)$. It can be easily concluded that the alkalis leachability values are fundamentally consistent with the secondary efflorescence levels of PCDMs. With the secondary efflorescence level of PCDM depressing, the alkalis leachability gradually decreases, and vice versa. Accordingly, the alkalis leachability can be used to qualitatively evaluate the 
secondary efflorescence levels of PCDMs, with a higher alkalis leachability value indicating a stronger secondary efflorescence trend. Moreover, PCDMs will exhibit visible secondary efflorescence when the alkalis leachability value is higher than $1 \mathrm{~g} /\left(\mathrm{m}^{2} \cdot \mathrm{h}\right)$.

\subsubsection{Effect of VAE on the alkalis leachability}

Fig. 5 illustrates the alkalis leachability of PCDMs cured for 1-360 d. For PCDM without VAE, with the curing age prolonging from $1 \mathrm{~d}$ to $7 \mathrm{~d}$, the alkalis leachability decreases from $2.3 \mathrm{~g} /\left(\mathrm{m}^{2} \cdot \mathrm{h}\right)$ to $1.43 \mathrm{~g} /\left(\mathrm{m}^{2} \cdot \mathrm{h}\right)$, and then gradually decreases with the curing age prolonging to $180 \mathrm{~d}$, but keeps constant from $180 \mathrm{~d}$ to $360 \mathrm{~d}$. For PCDM with $10 \%$ VAE, with the curing age prolonging from $1 \mathrm{~d}$ to $7 \mathrm{~d}$, the alkalis leachability decreases from $2.62 \mathrm{~g} /\left(\mathrm{m}^{2} \cdot \mathrm{h}\right)$ to $1.56 \mathrm{~g} /\left(\mathrm{m}^{2} \cdot \mathrm{h}\right)$, and then keeps constant with the curing age prolonging from $7 \mathrm{~d}$ to $360 \mathrm{~d}$.

When the curing age is no more than $7 \mathrm{~d}$, the alkalis leachability of PCDM with 10\% VAE is about $10 \%$ higher than that of PCDM without VAE. But with the curing age prolonging from $7 \mathrm{~d}$ to $360 \mathrm{~d}$, the alkalis leachability of PCDM with $10 \%$ VAE is much higher than that of PCDM without VAE, about four times at the curing age of $180 \mathrm{~d}$.
For PCDM without VAE cured for more than $28 \mathrm{~d}$, The alkalis leachability values all do not exceed $1 \mathrm{~g} /\left(\mathrm{m}^{2} \cdot \mathrm{h}\right)$, with no visible secondary efflorescence occurring. However, for PCDMs with 10\% VAE cured for 1-360 d, the alkalis leachability values all exceed $1 \mathrm{~g} /\left(\mathrm{m}^{2} \cdot \mathrm{h}\right)$, with visible secondary efflorescence on the PCDMs surface. This shows that VAE increases the alkalis leachability of PCDM, and accordingly aggravates the secondary efflorescence.

\subsection{Secondary efflorescence substances}

\subsubsection{Phases}

The XRD spectra of secondary efflorescence substances of PCDMs cured for $7 \mathrm{~d}$ are displayed in Fig. 6. For PCDM without or with $10 \%$ VAE, four diffraction peaks near $30^{\circ}(2 \theta)$ relate to $(\mathrm{K}$, Na) $\mathrm{AlSiO}_{4}$ (PDF 12-0197), $\mathrm{CaCO}_{3}$ (PDF 05-0586), and $\mathrm{K}_{2} \mathrm{SO}_{4}$ (PDF 05-0613), and the diffraction peak near $24^{\circ}$ relates to $\mathrm{KHCO}_{3}$. Moreover, in the XRD spectra of PCDM with $10 \%$ VAE, there are two diffraction peaks corresponding to $\mathrm{Al}_{2} \mathrm{Si}_{2} \mathrm{O}_{5}(\mathrm{OH})_{4}(\mathrm{PDF}$ 14-0164) and $\mathrm{Na}_{2} \mathrm{H}_{2} \mathrm{SiO}_{4} \cdot 4 \mathrm{H}_{2} \mathrm{O}$ (PDF 20-0579) near $12^{\circ}$ and $15^{\circ}$, respectively, while not being apparent in PCDM without VAE. Moreover, the $\mathrm{CaCO}_{3}$ peak is the strongest. It can be concluded that VAE does not

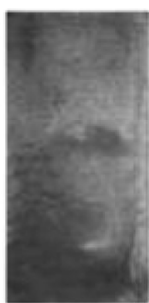

(a)

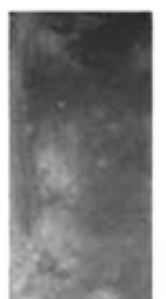

(b)

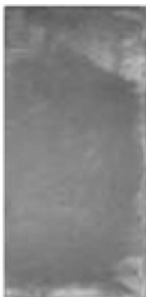

(c)

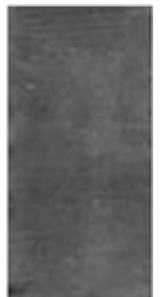

(d)

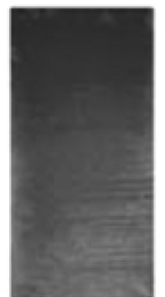

(e)

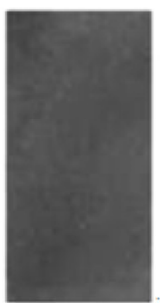

(f)

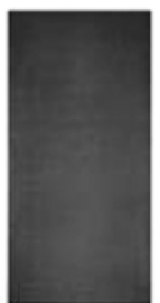

(g)

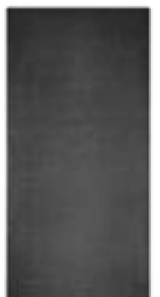

(h)

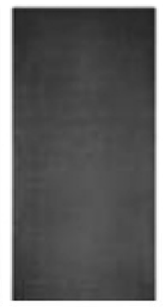

(i)

Fig. 3 Secondary efflorescence pictures of PCDMs cured for $7 \mathbf{~ d}$ (a) A1; (b) A2; (c) A3; (d) A4; (e) A5; (f) A6; (g) A7; (h) A8; (i) A9

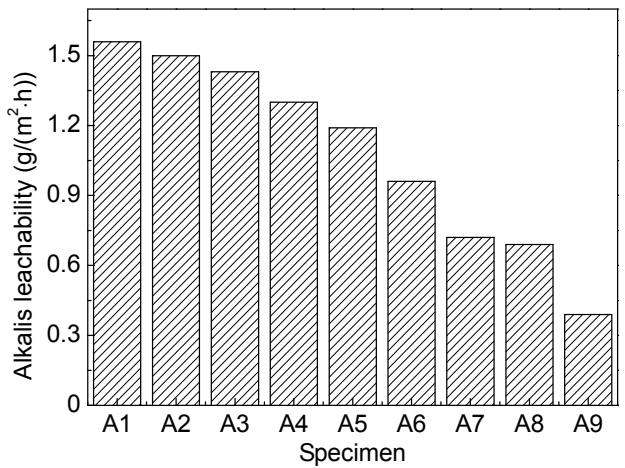

Fig. 4 Alkalis leachability of PCDMs cured for $7 \mathrm{~d}$

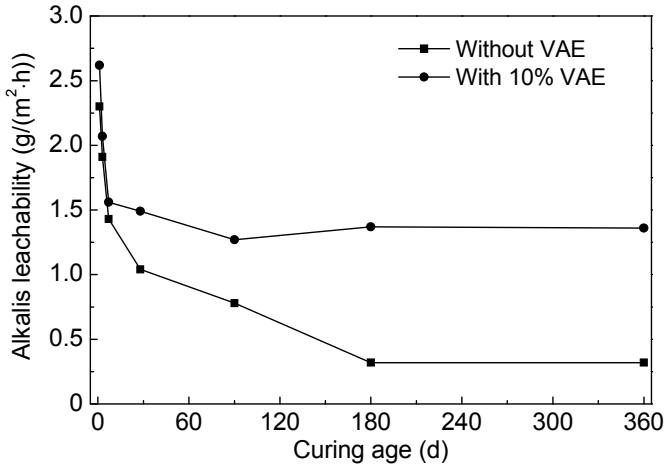

Fig. 5 Alkalis leachability of PCDMs 
affect the composition of secondary efflorescence substances, and $(\mathrm{K}, \mathrm{Na}) \mathrm{AlSiO}_{4}, \mathrm{CaCO}_{3}$, and $\mathrm{K}_{2} \mathrm{SO}_{4}$ are the main phases of secondary efflorescence substances for PCDM without or with VAE.

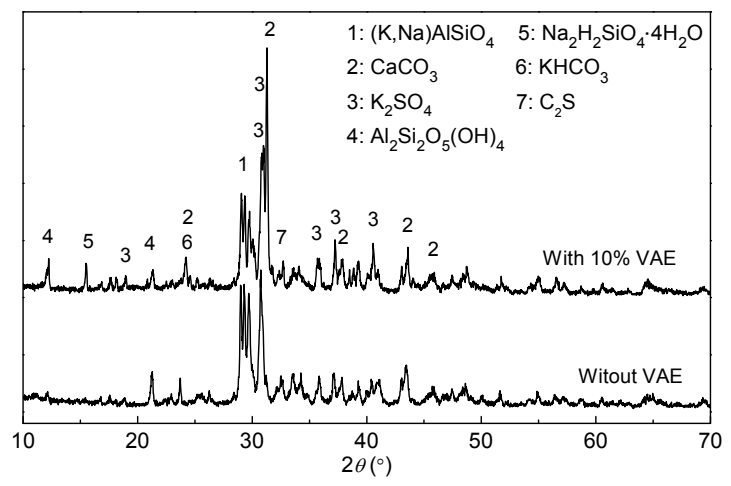

Fig. 6 XRD spectra of efflorescence substances

\subsubsection{Chemical composition}

The chemical composition of the secondary efflorescence substances in the surface leaching solution of PCDMs was also analyzed through XRF (Table 2). $\mathrm{Ca}^{2+}, \mathrm{K}^{+}$, and $\mathrm{Na}^{+}$are the main ions in the secondary efflorescence substances chemical composition for PCDM without or with 10\% VAE. The total content of the oxide composed by these three ions is $55.65 \%$ for PCDM without VAE, and $55.4 \%$ for PCDM with $10 \%$ VAE, with the content of $\mathrm{CaO}$ being more than $30 \%$. The contents of $\mathrm{CaO}, \mathrm{K}_{2} \mathrm{O}$, and $\mathrm{Na}_{2} \mathrm{O}$ in secondary efflorescence substances of PCDM with $10 \%$ VAE are almost the same as those of PCDM without VAE. Thus, it can be concluded that alkalis ions including $\mathrm{Ca}^{2+}, \mathrm{K}^{+}$, and $\mathrm{Na}^{+}$are the main sources inducing secondary efflorescence for PCDM. Moreover, VAE has little influence on the proportion of secondary efflorescence chemical compositions.

Table 2 Secondary efflorescence chemical composition in the surface leaching solution of PCDMs (in weight, \%)

\begin{tabular}{lllllll}
\hline Sample & $\mathrm{CaO}$ & $\mathrm{K}_{2} \mathrm{O}$ & $\mathrm{Na}_{2} \mathrm{O}$ & $\mathrm{SiO}_{2}$ & $\mathrm{SrO}$ & Total \\
\hline $\begin{array}{l}\text { Without } \\
\text { VAE }\end{array}$ & 30.2 & 18.0 & 7.45 & 2.53 & 0.38 & 58.56 \\
$\begin{array}{l}\text { With 10\% } \\
\text { VAE }\end{array}$ & 33.9 & 15.2 & 6.30 & 2.87 & 0.38 & 58.65 \\
\hline
\end{tabular}

\subsubsection{Morphology}

The morphology of the visible secondary efflorescence zone on the surface of PCDM with $10 \%$
VAE observed by SEM is shown in Fig. 7. A large number of granular particles uniformly distribute on the surface. Morphologies of these particles and the corresponding energy dispersive spectroscopy (EDS) analysis are presented in Fig. 8. It can be seen that these particles have different shapes and typical crystal structures. The spheroidal particles shown in Fig. 8a with the atomic ratio of $\mathrm{O}$ and $\mathrm{Ca}$ about 3 are probably $\mathrm{CaCO}_{3}$ particles. The petal-shaped particles shown in Fig. $8 \mathrm{~b}$ are caused by the deformation of $\mathrm{CaCO}_{3}$ particles possessing a hexagonal plate-like structure (Yang et al., 2007), with the atomic ratio of $\mathrm{O}$ and $\mathrm{Ca}$ about 4 . The plate-like particles shown in Fig. 8c may also be $\mathrm{CaCO}_{3}$ particles, with the atomic proportion of $\mathrm{O}$ and $\mathrm{Ca}$ being about 4 . This further indicates that $\mathrm{CaCO}_{3}$ particles are the main ingredient of secondary efflorescence substances; they distribute uniformly on the surface of PCDM to form visible secondary efflorescence.

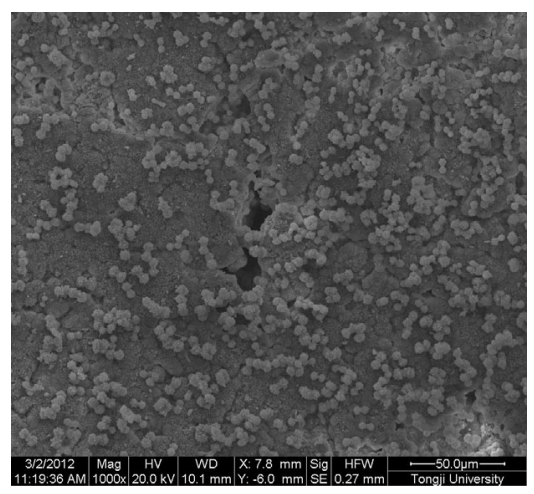

Fig. 7 Morphology of secondary efflorescence zone

\subsection{Soluble components inside PCDM}

Alkali ions such as $\mathrm{Ca}^{2+}, \mathrm{K}^{+}$, and $\mathrm{Na}^{+}$are the sources inducing secondary efflorescence for PCDM (Zhu et al., 2014). The $\mathrm{Ca}^{2+}, \mathrm{K}^{+}$, and $\mathrm{Na}^{+}$ concentration, $\mathrm{pH}$ value, and the content of the soluble salts inside the PCDMs are listed in Fig. 9. For PCDM without or with $10 \%$ VAE, with the curing age extending from $1 \mathrm{~d}$ to $28 \mathrm{~d}$, the $\mathrm{Ca}^{2+}, \mathrm{K}^{+}$, and $\mathrm{Na}^{+}$ concentrations all decreased in a large amount, with the $\mathrm{Ca}^{2+}$ concentration being much higher than the $\mathrm{K}^{+}$ and $\mathrm{Na}^{+}$concentrations (Figs. 9a and 9b), $\mathrm{pH}$ values slightly decrease (Fig. 9c), and the content of soluble salts increases from $14.7 \mathrm{mg} / \mathrm{g}$ to $25.2 \mathrm{mg} / \mathrm{g}$ for PCDM without VAE, while it is the highest for PCDM with $10 \%$ VAE cured for $7 \mathrm{~d}$. It can be 

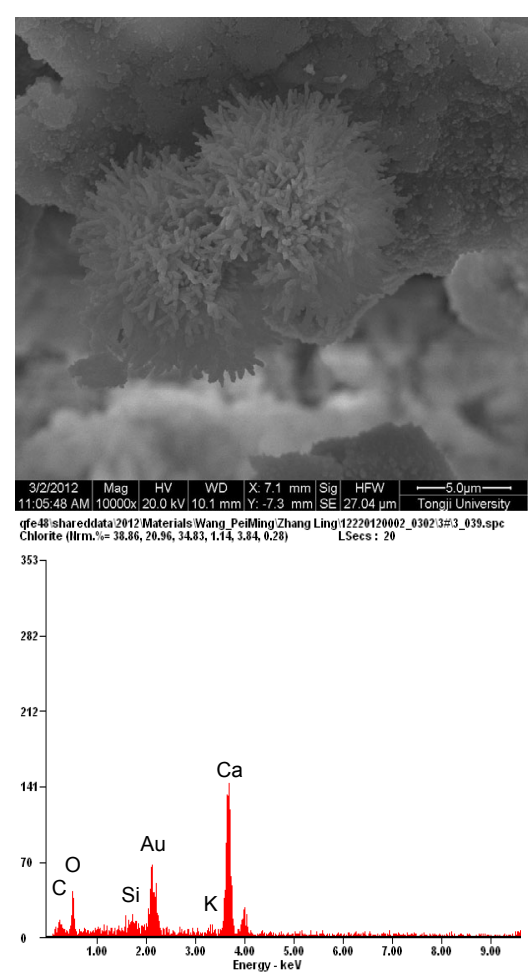

(a)
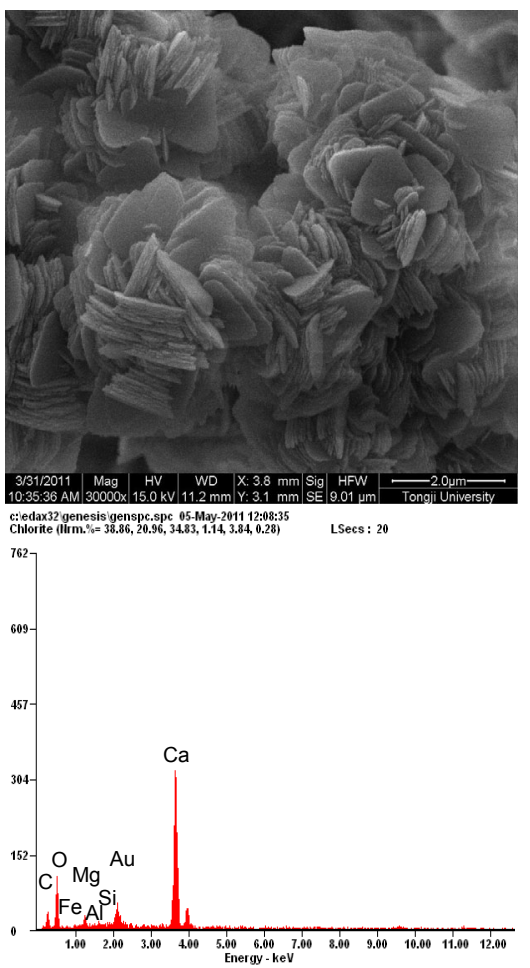

(b)
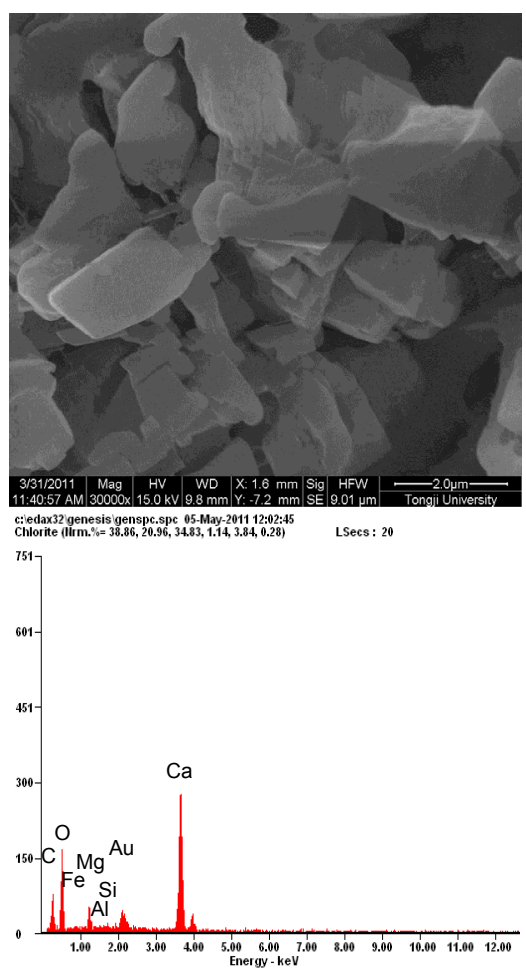

(c)

Fig. 8 Morphology and EDS analysis of secondary efflorescence particles
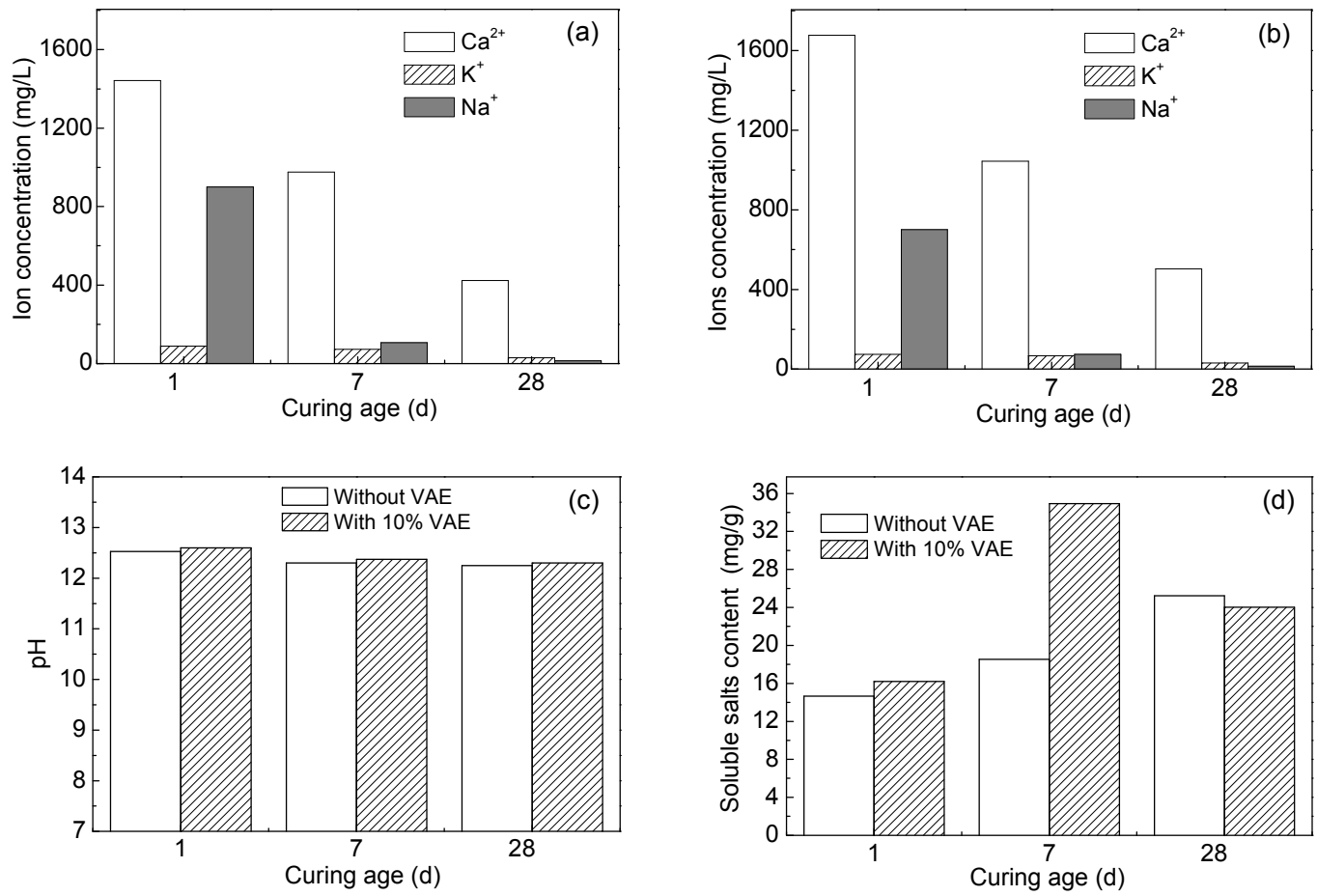

Fig. 9 Content of soluble components inside PCDMs

(a) Ions concentration in PCDM without VAE; (b) Ions concentration in PCDM with 10\% VAE; (c) pH; (d) Content of soluble salts 
concluded that with the curing age being extended, the sources inducing secondary efflorescence inside PCDM gradually decrease. To compare these two PCDMs, it can be seen that VAE increases the concentrations of alkalis ions, such as $\mathrm{Ca}^{2+}, \mathrm{K}^{+}$, and $\mathrm{Na}^{+}$, inside PCDM, accordingly raising the risk of visible secondary efflorescence. The reasons may be attributed to the following: first, VAE decreases the cement hydration degree in PCDM, resulting in a relatively high content for the unhydrated cement particles (Wang et al., 2005), and then re-hydration and dissolution of the unhydrated cement particles increase the alkalis content; second, VAE increases the porosity of PCDM (Silva et al., 2002), to increase the alkalis dissolved in the pore solution.

\subsection{Capillary water translocation}

The transmission of alkalis with pore water is the dominant factor influencing the forming of secondary efflorescence for PCDM. The capillary water loss rate of PCDMs is shown in Fig. 10. For PCDM without VAE, with the curing age extending from $1 \mathrm{~d}$ to $180 \mathrm{~d}$, the capillary water loss rate decreases from $1.98 \mathrm{~kg} / \mathrm{m}^{2}$ to $1.28 \mathrm{~kg} / \mathrm{m}^{2}$, and then it slightly declines with the curing age extending from $180 \mathrm{~d}$ to $360 \mathrm{~d}$. For PCDM with $10 \% \mathrm{VAE}$, with the curing age extending from $1 \mathrm{~d}$ to $180 \mathrm{~d}$, the capillary water loss rate decreases from $1.81 \mathrm{~kg} / \mathrm{m}^{2}$ to $0.96 \mathrm{~kg} / \mathrm{m}^{2}$, but it slightly rises at the curing age of $360 \mathrm{~d}$. It can be concluded that VAE can significantly decrease the capillary water loss rate of PCDM at the curing age of $1 \mathrm{~d}-360 \mathrm{~d}$, namely, to inhibit the translocation of pore water to the PCDM surface.

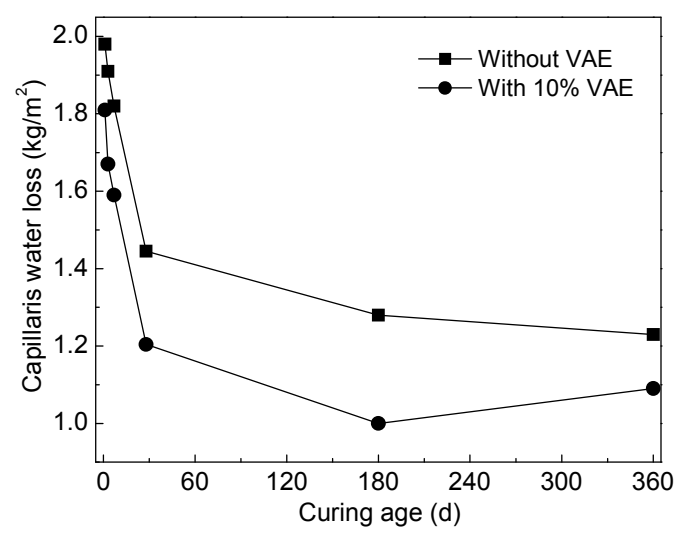

Fig. 10 Capillary water loss rate of PCDMs
VAE inhibits the translocation of pore water to the surface, but increases the alkalis leachability of PCDM, which accordingly promotes the secondary efflorescence of PCDM. The reasons may be due to the fact that VAE promotes the migration of ions in the pore solution and increases the capacity of pore water transmitting alkali ions.

\section{Conclusions}

The alkalis leachability can be used to quantitatively evaluate the secondary efflorescence levels of PCDMs, with higher alkalis leachability value indicating a stronger secondary efflorescence trend. With the alkalis leachability higher than $1 \mathrm{~g} /\left(\mathrm{m}^{2} \cdot \mathrm{h}\right), \mathrm{PCDMs}$ will display visible secondary efflorescence.

Alkalis ions including $\mathrm{Ca}^{2+}, \mathrm{K}^{+}$, and $\mathrm{Na}^{+}$are the main sources inducing secondary efflorescence for PCDM without or with VAE.

VAE increases the total concentrations of the $\mathrm{Ca}^{2+}, \mathrm{K}^{+}$, and $\mathrm{Na}^{+}$ions inside PCDM, promotes their mobility to the surface, improves the ability of pore water transmitting ions, and accordingly increases the alkalis leachability, and promotes the secondary efflorescence of PCDM.

\section{References}

Chandra, S., Flodin, P., 1987. Interactions of polymers and organic admixtures on Portland cement hydration. $\mathrm{Ce}$ ment and Concrete Research, 17(6):875-890. [doi:10. 1016/S0008-8846(87)90076-7]

DIN52617:1987. Determination of the Water Absorption Coefficient of Building Materials. Beuth-Verlag, Berlin.

Dow, C., Glasser, F.P., 2003. Calcium carbonate efflorescence on Portland cement and building materials. Cement and Concrete Research, 33(1):147-154. [doi:10.1016/S00088846(02)00937-7]

GB/T2015:2005. White Portland Cement. National Standardization Management Committee, China.

ISO 679:2009. Cement-Test Methods-Determination of Strength. International Organization for Standardization.

Kani, E.N., Allahverdi, A., Provis, J.L., 2012. Efflorescence control in geopolymer binders based on natural pozzolan. Cement \& Concrete Composites, 34(1):25-33. [doi:10. 1016/j.cemconcomp.2011.07.007]

Kresse, P., 1987. Efflorescence-mechanism of occurrence and possibilities of prevention. Betonwerk und FertigteilTechnik, 53:160-168. 
Larbi, J.A., Bijen, J.M., 1990. Interaction of polymers with Portland cement during hydration: a study of the chemistry of the pore solution of polymer-modified cement systems. Cement and Concrete Research, 20(1):139-147. [doi:10.1016/S0008-8846(90)90124-G]

Liu, J.C., Gai, G.Q., 2011. The mechanics research of decorative mortar. Journal of Jilin Institute of Architecture \& Civil Engineering, 28(2):72-74 (in Chinese).

Sghaier, N., Prat, M., 2009. Effect of efflorescence formation on drying kinetics of porous media. Transport in Porous Media, 80(3):441-454. [doi:10.1007/S11242-009-9373-6]

Silva, D.A., Roman, H.R., Gleize, P.J.P., 2002. Evidences of chemical interaction between VAE and hydrating Portland cement. Cement and Concrete Research, 32(9): 1383-1390. [doi:10.1016/S0008-8846(02)00805-0]

Wang, P.M., Zhang, G.F., Zhang, Y.M., 2005. Influence of polymer powders on mechanical properties of cement mortar. New Building Materials, 2005(1):32-36 (in Chinese). [doi:10.3969/j.issn.1001-702x.2005.01.011]

Yang, H., Jin, D.L., Ma, Z.J., et al., 2007. Effects of additives on morphology and crystal structure of calcium carbonate particles. Journal of Zhejiang Sci-Tech University, 24(5): 449-552 (in Chinese).

Zhu, H.M., Wang, P.M., Wang, R., et al., 2014. Effects of two redispersible polymer powders on early efflorescence of Portland cement-based decorative mortar. Materials Science, 20(3):345-350. [doi:10.5755/j01.ms.20.3.4053]

\section{中文概要}

题 目: 醋酸乙烯/乙烯共聚可再分散乳胶粉对硅酸盐水 泥基饰面砂浆二次泛白的影响

目 的: 采用碱浸出量定量评价醋酸乙烯/乙烯共聚可再分 散（VAE）乳胶粉对硅酸盐水泥基饰面砂浆二次 泛白的影响, 并分析其作用机理。

创新点: 采用定量化手段评价硅酸盐水泥基饰面砂浆的二 次泛白程度。

方 法: 1. 采用碱浸出率方法定量评价硅酸盐水泥基饰面 砂浆的二次泛白程度; 2. 采用水浸取法测试硅酸 盐水泥基饰面砂浆内部可溶性 $\mathrm{Ca}^{2+} 、 \mathrm{~K}^{+}$和 $\mathrm{Na}^{+}$的 含量, $\mathrm{pH}$ 值及可溶性物质总含量等; 3. 以硅酸盐 水泥基饰面砂浆毛细孔失水速率表征其内部水 的蒸发速率。

结 论: 1. 硅酸盐水泥基饰面砂浆的碱浸出量可用于定量 评价其二次泛白程度, 碱浸出量越大, 二次泛白 越严重; 当碱浸出量大于 $1 \mathrm{~g} /\left(\mathrm{m}^{2} \cdot \mathrm{h}\right)$ 时, 硅酸盐水 泥基饰面砂浆会呈现出可见二次泛白; $2 . \mathrm{Ca}^{2+}$, $\mathrm{K}^{+}$和 $\mathrm{Na}^{+}$等碱离子是导致硅酸盐水泥基饰面砂浆 二次泛白的主要根源; 3. VAE 乳胶粉增加了硅酸 盐水泥基饰面砂浆内部 $\mathrm{Ca}^{2+}, \mathrm{K}^{+}$和 $\mathrm{Na}^{+}$等碱离子 的含量, 并且促进它们向表面迁移, 增加了碱浸 出率, 从而促进二次泛白。

关键词: 硅酸盐水泥基饰面砂浆; VAE 乳胶粉; 二次泛白; 碱浸出率 